UDC 621.865 .8

DOI: $10.15587 / 2706-5448.2021 .240261$

Article type «Reports on Research Projects»

\section{Volodymyr Shvets, Viktor Tkachov}

\title{
DEVELOPMENT A MODEL OF ROBOT MOVEMENT WITH FIVE DEGREES OF FREEDOM FOR A WAREHOUSE
}

The object of research is a mathematical model describing the movement of a robot with five degrees of freedom for a warehouse. The work was aimed at analyzing the kinematic structure of the manipulator, on the basis of which the base and local coordinate systems were selected, as well as further formalized recording of the kinematic equations in matrix form. It is noted that one of the most problematic places is that the algorithms for controlling the robot most often contain local rules for the interaction of robots between themselves and the external environment, and emergent behavior is manifested as a result of the application of these rules, which does not have a formal description. Therefore, it is important to modernize the models describing the motion of a robot with five degrees of freedom for a warehouse. Using the matrix method, the sequence of constructing coordinate systems is described and its mathematical description is given, which will make it possible to eliminate this drawback in the future. The computer implementation of the developed algorithms was carried out using methods for processing matrix data structures. The principle of constructing a kinematic model of a robot is presented, with the help of which the main coordinate transformation matrices are obtained for robot with five degrees of freedom, and the possibility of taking into account the size of the gaps in the joints is shown. The resulting model is obtained, which is proposed for use in building control algorithms for a robot with an automatic gap selection, as well as in robot calibration. This is due to the fact that the proposed model has a number of features, in particular, the basic coordinate system and the coordinate system of each link of robot with five degrees of freedom are taken into account. This makes it possible to obtain the values of the indicators for the projection of the robot position vector in the initial state, in the rotation of the fourth link at a well-defined angle and in the case of a vertically straightened manipulator. Compared to similar known studies, this provides advantages such as minimizing errors in position, speed and motion accuracy.

Keywords: robot control algorithm, degrees of freedom, orthonormal coordinate system, Denavit-Hartenberg transformations.

How to cite

Shvets, V., Tkachov, V. (2021). Development a model of robot movement with five degrees of freedom for a warehouse. Technology Audit and Production Reserves, 5 (1 (61)), 12-17. doi: http://doi.org/10.15587/2706-5448.2021.240261

\section{Introduction}

With the development of robotics, fundamentally new possibilities open up for the formation of a spatial structure from individual fully functional homogeneous robotic units, adapted to the solution of a specific applied problem at a certain place and at a certain moment in time. Robot motion control is a large field of robotics with many open questions. This area is attracting a lot of attention due to the development of wireless communication technologies, the high availability of mobile robots and the advantages they have in solving complex problems (for example, resistance to accidents, the ability to solve several problems, scalability) [1].

Robots with five to six degrees of freedom are widely used in various industries at various stages of the production chain at textile and light industry enterprises [2] and at food industry enterprises [3]. The solution to the problems of controlling the movement of the robot is considered using mathematical models of various robotic manipulators [4, 5]. However, one of the open questions is the task of bringing the gripper to a given point in space and taking the load. Robot control algorithms most often contain local rules for the interaction of robots between themselves and the external environment, and the holistic behavior is manifested as a result of the application of these rules and has no formal description [6]. Thus, in the parameters of the algorithm there is no explicit interpretation regarding the behavior of the entire group, which complicates the tuning of the algorithm. To achieve optimal movement to the target point, optimization by the particle swarm method is proposed [7]. Thus, the object of research is a mathematical model that describes the movement of robot with five degrees of freedom for a warehouse. The aim of research is to create a model of robot motion with five degrees of freedom for a warehouse. 


\section{Methods of research}

To solve the set objectives, the analysis of scientific literature and methods of digital signal processing are used. The computer implementation of the developed algorithms is carried out using methods for processing matrix data structures.

\section{Research results and discussion}

To effectively control a robot, it is necessary to have an accurate kinematic model. At present, approaches to the formulation of equations describing the kinematics of robots are widely used and well-studied, the most widespread are the Denavit-Hartenberg transformations. This method of mathematical description is quite general and requires specification for each type of robot [8].

Currently existing industrial robots, as a rule, have five to six degrees of mobility.

To draw up a kinematic model of the robot's movement with five degrees of freedom for the warehouse, the base coordinate system and the coordinate system of each link are specified. The basic coordinate system is called the «zero» coordinate system $\left(x_{0}, y_{0}, z_{0}\right)$, which is an inertial coordinate system of the robot. As for each link, then on the axis of their articulation define a Cartesian orthonormal coordinate system $\left(x_{i}, y_{i}, z_{i}, l\right)$, where $i=1,2, \ldots, n$, and $n$ is equal to the number of degrees of freedom of robot. For the case with a rotary joint, which has only one degree of freedom, each coordinate system $\left(x_{i}, y_{i}, z_{i}\right)$ of the robot corresponds to an $(i+1)$ joint and is associated with the $i$ link. When the electric drive drives the $i$-joints, the $i$ link begins to move along the $(i-1)$ link, and since the $i$ coordinate system is associated with the $i$ link, it moves with it. It is also true that the $\mathrm{n}$ coordinate system moves with the last $\mathrm{n}$ link of the robot.

To describe the rotational and translational connections between neighboring links of Denavit and Hartenberg (DHrepresentation), a matrix method was proposed for the sequential construction of coordinate systems associated with each link of the kinematic chain [9]. The meaning of these representations is to form a homogeneous transformation matrix, has a dimension of $4 \times 4$ and describes the position of the coordinate system of each link in the coordinate system of the previous link. So, Fig. 1 shows a schematic representation of the link coordinate system and its parameters in accordance with the Denavit-Hartenberg transformation.

Fig. 1 shows the joint of the link and with the link $(i-1)$ and shows the coordinate system and the link and its parameters according to the $\mathrm{DH}$ representation. It is obvious that each $i$-joint of the robot connects two links $(i-1)$ and $i$. To understand the logic of robot with coordinate systems tied to the links of the robot, let's emphasize that the $i$-coordinate system is rigidly associated with the $i$-link. When the $i$-link is driven by the $i$-joint, the coordinate system and changes its position relative to the previous system $(i-1)$. Let's note that this image shows the binding of the $i$-coordinate system to the $i$-link. Let's note that this binding applies to all but the last link. That is, the link and, which is shown in Fig. 1, cannot be the last, but only be in the position from the first to the penultimate. This makes it possible to consistently convert the coordinates of the robot capture from the frame of reference associated with the last link, in the basic frame of reference, which is the inertial coordinate system for this dynamic system [10]. Thus, for robot with five degrees of freedom, six coordinate systems must be defined, namely $\left(x_{0}, y_{0}, z_{0}\right)$, $\left(x_{i}, y_{i}, z_{i}\right), \ldots,\left(x_{6}, y_{6}, z_{6}\right)$.

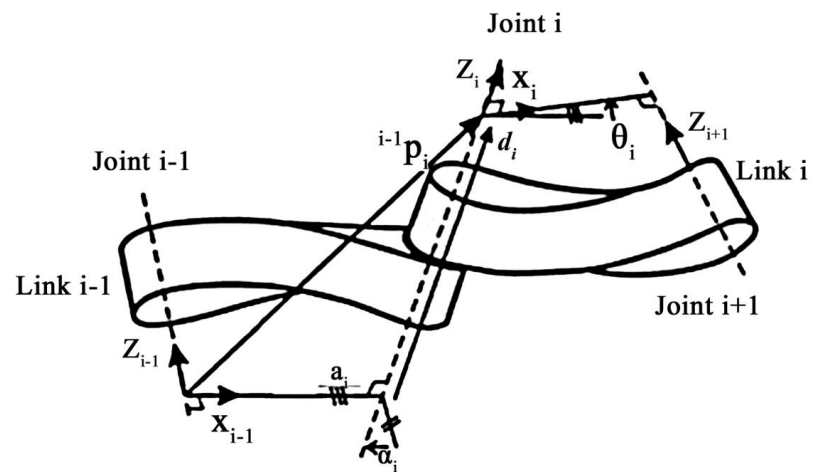

Fig. 1. Schematic representation of the link coordinate system and its parameters in accordance with the Denavit-Hartenberg transformation

Each coordinate system is formed based on the following three rules:

1) $z_{i-1}$ axis is directed along the $i$-joint axis;

2) $x_{i}$ axis is perpendicular to the $z_{i-1}$ axis and its direction is taken either along the $i$-link or perpendicular to it,

3) $y_{i}$ axis complements the $x_{i}$ and $z_{i}$ axes to the Cartesian coordinate system.

These rules leave freedom in the choice of the 0 -th coordinate system, provided that the $z_{0}$ axis is directed along the axis of the first joint. The latter, $n$-coordinate system can also be chosen at an arbitrary point in $n$-link, provided that the $x_{n}$ axis is perpendicular to the $z_{n-1}$ axis.

These rules for describing links depend on four geometric parameters corresponding to each link. Any rotational or translational movement is fully described by a set of four parameters, which are determined in accordance with Fig. 2, $b$ as follows:

1) $a_{i}$-linear displacement - the distance from $z_{i-1}$ to $z_{i}$ along $x_{i-1}$;

2) $a_{i}$-angular shift - the angle by which the $z_{i-1}$ axis must be rotated around the $x_{i}$ axis so that it becomes collinear with the $z_{i}$ axis (the sign is determined in accordance with the right hand rule);

3) $d_{i}$ - the distance from the $x_{i-1}$ axis to the $x_{i}$ axis, which is measured along the $z$ axis;

4) $\theta_{i}$-connected angle - the angle by which the $x_{i-1}$ axis must be rotated around the $z_{i}$ axis so that it becomes collinear with the $x_{i}$ axis (the sign is determined according to the right-hand rule).

For rotating joints, the parameters $d_{i}, a_{i}$ and $\alpha_{i}$ are the characteristics of the joint, they are called the attached parameters, emphasizing that they are constant for the investigated robot. At the same time, $\theta_{i}$ is a variable and changes with the rotation of $i$-link relative to $(i-1)$ link. The value of $\theta_{i}$ is evidenced by the attached variable, which can change its value.

Based on the above-stated basic rules for constructing orthonormal coordinate systems of links, as well as taking into account the geometric meaning of the parameters of joints and links, an orthonormal coordinate system of the robot was formed. Coordinate systems are numbered in ascending order - from base to robot gripping (Fig. 2, $b$ ). The proposed method for choosing coordinate systems is not the only one $[10,11]$. 


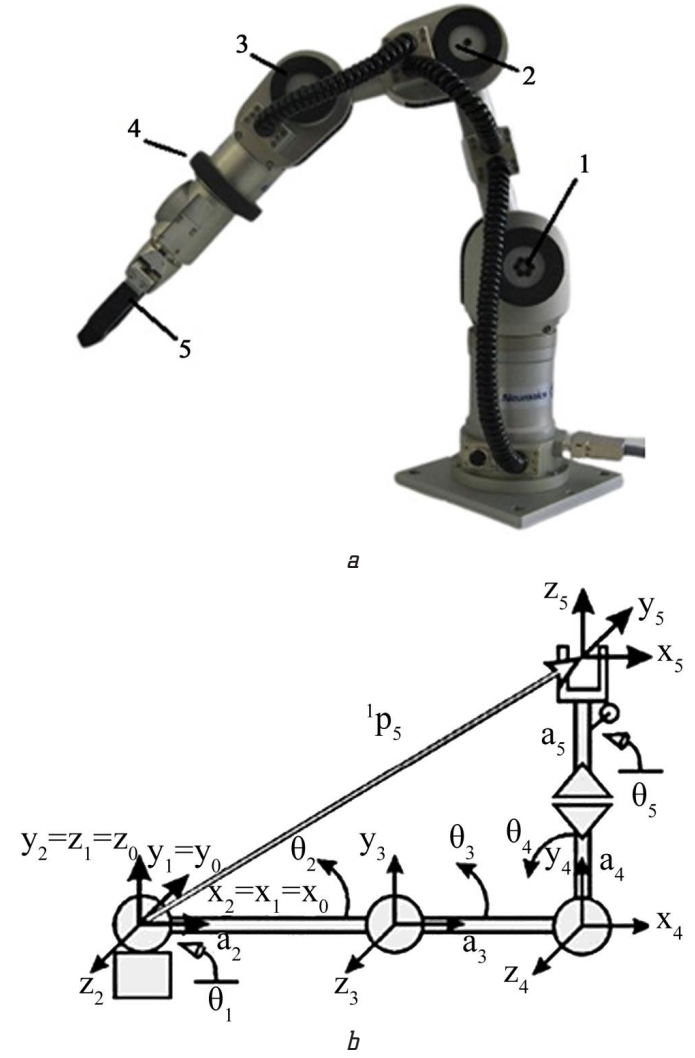

Fig. 2. The investigated robot:

$a$ - appearance; $b$ - corresponding motion coordinate systems

Based on the characteristics and using the formula for calculating the moment, the values of the moments of each robot joint were obtained, which are presented in Table 1.

Table 1

Basic values and coordinates of robot kinematics with five degrees of freedom

\begin{tabular}{|c|c|c|c|c|c|}
\hline Joint $i$ & $d_{i}$ & $a_{i}$ & $\alpha_{i}$ & $\begin{array}{c}\text { Limits of change } \\
\text { of angles }\end{array}$ & $\begin{array}{l}\text { Nominal } \\
\text { moment }\end{array}$ \\
\hline 1 & 0 & 0 & 90 & +1027-30 & $18.03 \mathrm{Nm}$ \\
\hline 2 & 0 & $a_{2}$ & 0 & $+/-122.5^{\circ}$ & $8.12 \mathrm{Nm}$ \\
\hline 3 & 0 & $a_{3}$ & 0 & $+/-112^{\circ}$ & $4.46 \mathrm{Nm}$ \\
\hline 4 & $a_{4}+a_{5}$ & 0 & -90 & $+/-168^{\circ}$ & $0.31 \mathrm{Nm}$ \\
\hline 5 & \multicolumn{3}{|c|}{ Gearing } & $+299.5^{\circ} /-29.5^{\circ}$ & $0.31 \mathrm{Nm}$ \\
\hline
\end{tabular}

At present, it is known that the coordinates of the point $r_{i}$, given in the $i$-coordinate system, can be transformed into the coordinates of the point $r_{i-1}$ in the $(i-1)$-coordinate system, performing the following sequence of operations:

1) $\operatorname{ROT}\left(\alpha_{i}\right)$ - rotation around the $x_{i}$ axis - by the angle $a_{i}$;

2) TRANS $\left(a_{i}\right)$ - displacement along the $x_{i-1}$ axis by the distance $a_{i}$;

3) $\operatorname{ROT}\left(\theta_{\mathrm{i}}\right)$ - rotation around the $z_{i}$ axis by an angle $d_{i}$;

4) TRANS $\left(d_{i}\right)$ - displacement along the $z_{i}$ axis by the distance $d_{i}$.

Each of these four operations can be described by a homogeneous matrix of elementary rotation or displacement, and the product of such matrices will give a homogeneous complex transformation matrix ${ }^{i-1} A_{i}$, called the DH transformation matrix for adjacent coordinate systems numbered ${ }^{i-1} A_{i}$. Thus, let's obtain:

$$
\begin{aligned}
& { }^{i-l} A=T_{z, d} T_{z, \theta} T_{x, a} T_{x, \alpha}= \\
& =\operatorname{ROT}\left(\alpha_{i}\right) \operatorname{TRANS}\left(a_{i}\right) \operatorname{ROT}\left(\theta_{i}\right) \operatorname{TRANS}\left(d_{i}\right)= \\
& =\left[\begin{array}{cccc}
1 & 0 & 0 & 0 \\
0 & \cos \alpha_{i} & -\sin \alpha_{i} & 0 \\
0 & \sin \alpha_{i} & \cos \alpha_{i} & 0 \\
0 & 0 & 0 & 1
\end{array}\right] \times\left[\begin{array}{cccc}
1 & 0 & 0 & a_{i} \\
0 & 1 & 0 & 0 \\
0 & 0 & 1 & 0 \\
0 & 0 & 0 & 1
\end{array}\right] \times \\
& \times\left[\begin{array}{cccc}
\cos \theta_{i} & -\sin \theta_{i} & 0 & 0 \\
\sin \theta_{i} & \cos \theta_{i} & 0 & 0 \\
0 & 0 & 1 & 0 \\
0 & 0 & 0 & 1
\end{array}\right] \times\left[\begin{array}{cccc}
1 & 0 & 0 & 0 \\
0 & 1 & 0 & 0 \\
0 & 0 & 1 & d_{i} \\
0 & 0 & 0 & 1
\end{array}\right]= \\
& =\left[\begin{array}{cccc}
\cos \theta_{i} & -\sin \theta_{i} & 0 & a_{i} \\
\cos \alpha_{i} \sin \theta_{i} & \cos \alpha_{i} \cos \theta_{i} & -\sin \alpha_{i} & -d_{i} \sin \alpha_{i} \\
\sin \alpha_{i} \sin \theta_{i} & \sin \alpha_{i} \cos \theta_{i} & \cos \alpha_{i} & d_{i} \cos \alpha_{i} \\
0 & 0 & 0 & 1
\end{array}\right] .
\end{aligned}
$$

Based on the matrix ${ }^{i-1} A_{i}$ transformation of adjacent coordinate systems and taking into account the parameters of the robot kinematics (Table 1), let's obtain homogeneous transformation matrices of coordinate systems of links of three robot configurations. The transformation matrices of coordinates from the first to the fourth links ${ }^{i-1} A_{i}$ are identical for all three robot configurations. The ${ }^{4} A_{5}$ matrix does not make sense for the robot configuration, because its grabber is directed from the fifth link and its length is already taken into account in the ${ }^{4} A_{5}$ matrix:

$$
\begin{aligned}
{ }^{0} A_{1} & =\left[\begin{array}{cccc}
\cos \left(\theta_{1}\right) & -\sin \left(\theta_{1}\right) & 0 & 0 \\
\sin \left(\theta_{1}\right) & \cos \left(\theta_{1}\right) & 0 & 0 \\
0 & 0 & 1 & 0 \\
0 & 0 & 0 & 1
\end{array}\right] ; \\
{ }^{1} A_{2} & =\left[\begin{array}{cccc}
\cos \left(\theta_{2}\right) & -\sin \left(\theta_{2}\right) & 0 & 0 \\
0 & 0 & -1 & 0 \\
\sin \left(\theta_{2}\right) & \cos \left(\theta_{2}\right) & 0 & 0 \\
0 & 0 & 0 & 1
\end{array}\right] ; \\
{ }^{2} A_{3} & =\left[\begin{array}{cccc}
\cos \left(\theta_{3}\right) & -\sin \left(\theta_{3}\right) & 0 & a_{2} \\
\sin \left(\theta_{3}\right) & \cos \left(\theta_{3}\right) & 0 & 0 \\
0 & 0 & 1 & 0 \\
0 & 0 & 0 & 1
\end{array}\right] ; \\
{ }^{3} A_{4} & =\left[\begin{array}{cccc}
\cos \theta_{4} & -\sin \theta_{4} & 0 & a_{4} \\
\sin \theta_{4} & \cos \theta_{4} & 0 & 0 \\
0 & 0 & 1 & 0 \\
0 & 0 & 0 & 1
\end{array}\right] ; \\
{ }^{4} A_{5} & =\left[\begin{array}{cccc}
{ }^{4} A_{5} & =\left[\begin{array}{cccc}
\cos \theta_{5} & -\sin \theta_{5} & 0 & 0 \\
0 & 0 & 1 & a_{4}+a_{5} \\
-\sin \theta_{5} & -\cos \theta_{5} & 0 & 0 \\
0 & 0 & 0 & 1 \\
0 & -\sin \theta_{5} & 0 & 0 \\
-\sin \theta_{5} & -\cos \theta_{5} & 0 & 0 \\
0 & 0 & 0 & 1
\end{array}\right] ;
\end{array}\right.
\end{aligned}
$$


Using matrices ${ }^{i-1} A_{i}$, it is possible to associate the homogeneous coordinates $p_{i}$ of the point $p$ (which is in the 1st coordinate system) with the homogeneous coordinates $p_{i-1}$ relative to the $(i-1)$-frame associated with $(i-1)$-link. This relationship is established by the equation:

$$
p_{i-1}={ }^{i-1} A_{i} p_{i}
$$

where $p_{i-1}=\left(x_{i-1}, y_{i-1}, z_{i-1}, 1\right)^{T}$ and $p_{i}=\left(x_{i}, y_{i}, z_{i}, 1\right)^{T}$.

The product of homogeneous matrices of the form ${ }^{i-1} A_{i}$ is a homogeneous matrix ${ }^{0} T_{i}$, which determines the position of the $i$-coordinate system relative to the base:

$$
\begin{aligned}
& { }^{0} T_{i}={ }^{0} A_{1}{ }^{1} A_{2} \ldots{ }^{i-1} A_{i}=\prod_{j=1}^{i}{ }^{j-1} A_{j}= \\
& =\left[\begin{array}{cccc}
n_{i} & s_{i} & a_{i} & { }^{0} p_{i} \\
0 & 0 & 0 & 1
\end{array}\right]=\left[\begin{array}{cc}
{ }^{0} R_{i} & 0 \\
0 & p_{i} \\
0 & 1
\end{array}\right],
\end{aligned}
$$

where ${ }^{0} R_{i}=\left[\begin{array}{lll}n_{i} & s_{i} & a_{i}\end{array}\right]$ - matrix that determines the orientation of the 1 st coordinate system associated with the $i$-th link with respect to the base coordinate system (the upper left submatrix of the ${ }^{0} T_{i}$ matrix with a dimension of $3 \times 3) ;{ }^{0} T_{i}-$ vector connects the origin of the base coordinate system with the origin of the $i$-coordinate system (the upper the right submatrix of the matrix ${ }^{0} T_{i}$, which has dimension $3 \times 1$ ).

In particular, for $i=5$, let's obtain the matrix $T={ }^{0} A_{5}$, which determines the position and orientation of the robot grip according to the basic coordinate system. This matrix is often referred to as the «robot matrix»:

$$
\begin{aligned}
& T={ }^{0} A_{6}=\prod_{j=1}^{i}{ }^{j-1} A_{j}=\left[\begin{array}{cccc}
n & s & a & p \\
0 & 0 & 0 & 1
\end{array}\right]= \\
& =\left[\begin{array}{cccc}
n_{x} & s_{x} & a_{x} & p_{x} \\
n_{y} & s_{y} & a_{y} & p_{y} \\
n_{z} & s_{z} & a_{z} & p_{z} \\
0 & 0 & 0 & 1
\end{array}\right],
\end{aligned}
$$

where $p$ - vector of the gripping position; $p$ - normal vector to the gripping; $s$ - tangent vector of gripping; $a$ - approach vector.

The tangent vector $n$-gripping lies in the plane of movement of the gripping fingers and indicates the direction of movement of the fingers when opening and closing the gripper. The gripping approach vector $a$ is directed along the normal to the gripping plane, that is, perpendicular to the fastening of the tool in gripping. The gripping position vector $p$ is defined by a line from the origin of the base coordinate system to the origin of the gripping coordinate system, which is typically located at the point that is the geometric center of fully clenched fingers.

The solution of the direct problem of kinematics for robot according to the given formula leads to a single matrix $T$ for given values of $\theta$ and for the case of rotational joints under consideration. For each joint, the robot has known limitations, which are determined by the physical limits of variation of $\theta_{i}$.

Table 1 shows the following limits for the robot in relative coordinates for each joint, according to which there are the final equations:

$$
\left\{\begin{array}{l}
\left\{\begin{array}{l}
n_{x}=\cos \left(\theta_{1}\right) \cdot \cos \left(\theta_{2}\right) \cdot \cos \left(\theta_{3}\right) \cdot \cos \left(\theta_{4}\right) \cdot \cos \left(\theta_{5}\right)- \\
-\cos \left(\theta_{1}\right) \cdot \cos \left(\theta_{2}\right) \cdot \sin \left(\theta_{3}\right) \cdot \sin \left(\theta_{4}\right) \cdot \cos \left(\theta_{5}\right)- \\
-\cos \left(\theta_{1}\right) \cdot \sin \left(\theta_{2}\right) \cdot \cos \left(\theta_{3}\right) \cdot \sin \left(\theta_{4}\right) \cdot \cos \left(\theta_{5}\right)- \\
-\cos \left(\theta_{1}\right) \cdot \sin \left(\theta_{2}\right) \cdot \sin \left(\theta_{3}\right) \cdot \cos \left(\theta_{4}\right) \cdot \cos \left(\theta_{5}\right)- \\
-\sin \left(\theta_{1}\right) \cdot \sin \left(\theta_{5}\right), \\
n_{y}=\sin \left(\theta_{1}\right) \cdot \cos \left(\theta_{2}\right) \cdot \cos \left(\theta_{3}\right) \cdot \cos \left(\theta_{4}\right) \cdot \cos \left(\theta_{5}\right)- \\
-\sin \left(\theta_{1}\right) \cdot \cos \left(\theta_{2}\right) \cdot \sin \left(\theta_{3}\right) \cdot \sin \left(\theta_{4}\right) \cdot \cos \left(\theta_{5}\right)- \\
-\sin \left(\theta_{1}\right) \cdot \sin \left(\theta_{2}\right) \cdot \cos \left(\theta_{3}\right) \cdot \sin \left(\theta_{4}\right) \cdot \cos \left(\theta_{5}\right)- \\
-\sin \left(\theta_{1}\right) \cdot \sin \left(\theta_{2}\right) \cdot \sin \left(\theta_{3}\right) \cdot \cos \left(\theta_{4}\right) \cdot \cos \left(\theta_{5}\right)+ \\
+\cos \left(\theta_{1}\right) \cdot \sin \left(\theta_{5}\right), \\
n_{z}=\sin \left(\theta_{1}+\theta_{2}+\theta_{3}\right) \cdot \cos \left(\theta_{5}\right) ; \\
p_{y}=\frac{\left(+\left(a_{4}+a_{5}\right) \cdot\left(\begin{array}{l}
\cos \left(\theta_{1}+\theta_{2}+\theta_{3}+\theta_{4}\right)- \\
-\cos \left(\theta_{1}-\theta_{2}-\theta_{3}-\theta_{4}\right)
\end{array}\right)\right.}{2} \\
p_{z}=a_{2} \cdot\left(\sin \left(\theta_{2}\right)+a_{3} \cdot \sin \left(\theta_{2}+\theta_{3}\right)\right)+ \\
+\left(a_{4}+a_{5}\right) \cdot \cos \left(\theta_{2}+\theta_{3}+\theta_{4}\right) \cdot \\
-\cos \left(\theta_{1}\right) \cdot \cos \left(\theta_{2}\right) \cdot \cos \left(\theta_{3}\right) \cdot \cos \left(\theta_{4}\right) \cdot \sin \left(\theta_{5}\right)+ \\
+\cos \left(\theta_{1}\right) \cdot \sin \left(\theta_{2}\right) \cdot \cos \left(\theta_{3}\right) \cdot \sin \left(\theta_{4}\right) \cdot \sin \left(\theta_{5}\right)+ \\
+\cos \left(\theta_{1}\right) \cdot \sin \left(\theta_{2}\right) \cdot \sin \left(\theta_{3}\right) \cdot \cos \left(\theta_{4}\right) \cdot \sin \left(\theta_{5}\right)- \\
-\sin \left(\theta_{1}\right) \cdot \cos \left(\theta_{5}\right), \\
p_{y}=-\sin \left(\theta_{1}\right) \cdot \cos \left(\theta_{2}\right) \cdot \cos \left(\theta_{3}\right) \cdot \cos \left(\theta_{4}\right) \cdot \sin \left(\theta_{5}\right)+ \\
+\sin \left(\theta_{1}\right) \cdot \cos \left(\theta_{2}\right) \cdot \sin \left(\theta_{3}\right) \cdot \sin \left(\theta_{4}\right) \cdot \sin \left(\theta_{5}\right)+ \\
+\sin \left(\theta_{1}\right) \cdot \sin \left(\theta_{2}\right) \cdot \cos \left(\theta_{3}\right) \cdot \sin \left(\theta_{4}\right) \cdot \sin \left(\theta_{5}\right)+ \\
+\sin \left(\theta_{1}\right) \cdot \sin \left(\theta_{2}\right) \cdot \sin \left(\theta_{3}\right) \cdot \cos \left(\theta_{4}\right) \cdot \sin \left(\theta_{5}\right)+ \\
+\cos \left(\theta_{1}\right) \cdot \cos \left(\theta_{5}\right), \\
s_{z}=\frac{\cos \left(\theta_{2}+\theta_{3}+\theta_{4}+\theta_{5}\right)-\cos \left(\theta_{2}+\theta_{3}+\theta_{4}-\theta_{5}\right)}{2}, \\
\left\{\begin{array}{l}
a_{x}=-\sin \left(\theta_{1}+\theta_{2}+\theta_{3}+\theta_{4}\right)+ \\
a_{y}=\frac{\cos \left(\theta_{1}+\theta_{2}+\theta_{3}+\theta_{4}\right)-\cos \left(\theta_{1}-\theta_{2}-\theta_{3}-\theta_{4}\right)}{a_{z}=\cos \left(\theta_{2}+\theta_{3}+\theta_{4}\right) ;}
\end{array}\right.
\end{array}\right.
\end{array}\right.
$$

These equations make it possible to determine the final positions of the gripping on the basis of the coordinates of the individual joints of the robot. In the presence of a gap at the exit of the joints, the solution of this problem is much more complicated. In this paper, it is proposed to take into account the gap as follows:

$$
\theta_{i}=\theta_{i}^{\prime}+\delta \theta_{i}\left(M_{i}\right)
$$

where $\delta \theta_{i}\left(M_{i}\right)$ - deviation function of the connected angle, which describes the gap in the $i$-joint; $\theta^{\prime}{ }_{i}-$ angle in front of the gap; $\theta_{i}-$ angle at the exit of the joint. 
A typical dependence of the deviation of the connected angle on the moment in the presence of a gap in the joint is presented in Fig. 3.

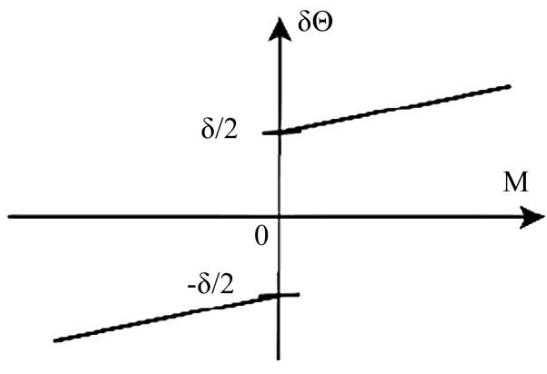

Fig. 3. The gap in the robot joint

Fig. 3 shows that in the presence of a gap at the outlet of the joints there is a gradual deviation of the connected angle, which describes the gap in the $i$-joint. Moreover, the deviation increases with increasing torque acting on the $i$-joint. However, it is known that in movable joints set a guaranteed gap that provides mutual movement of the robot links, to accommodate the layer of oil, taking into account the specific conditions of power and kinematic parameters of the connection, thermal regime, accuracy of geometric parameters, location and surface roughness. Therefore, the presence of a gap when creating a mathematical model cannot be neglected. But the increase in the gap leads to a deterioration in the accuracy of positioning, which is why it is necessary to select the optimal values of the gap for efficient operation of the robot.

The mathematical description of the characteristic of the moment acting on the $i$-joint has the form:

$$
\delta \theta_{i}\left(M_{i}\right)=\delta \cdot\left(\frac{1}{2} \cdot \operatorname{sign}\left(M_{i}\right)+k \frac{M_{i}}{M_{H i}}\right)
$$

where $\operatorname{sign}\left(M_{i}\right)$ - function of the moment sign acting on the $i$-joint; $\delta$ - value of the mechanical gap from the output shaft of the gearbox (for Maxon gearboxes used in the robots, it is $0.035 \mathrm{rad}$. in the absence of load); $k_{N}=0.05+0.4-$ coefficient depending on the material of the gears and the design of the gearbox; $k_{N}=$ nominal output moment of the $i$-joint.

Estimation of the behavior of the model at the initial gap $\delta=0$ is performed on the basis of projections of the vector of the grapping position. Using the matrix, the projections of the position vector were calculated. This operation is implemented for the initial state and for the rotation of the fourth link by an angle $\pi / 2$ clockwise, as well as for the case of a vertically rectified robot [4].

For the initial position of the system are connected angles equal:

$$
\theta=\left(\theta_{1}, \theta_{2}, \theta_{3}, \theta_{4}, \theta_{5}\right)^{T}=(0,0,0,0,0)^{T},
$$

substituting their values into the equation, let's obtain the projections of the gripping position vector:

$$
p=\left(p_{x}, p_{y}, p_{z}\right)^{T}=\left(a_{2}+a_{3}, \quad 0, \quad a_{4}+a_{5}\right)^{T} .
$$

For the second case-position after rotation - the attached angles $\theta=(0,0,0,-\pi / 2,0)^{T}-$ vector of the gripping position will be equal to:

$$
p=\left(p_{x}, p_{y}, p_{z}\right)^{T}=\left(a_{2}+a_{3}+a_{4}+a_{5}, \quad 0,0\right)^{T} .
$$

Robot in a vertical position:

$$
p=\left(p_{x}, p_{y}, p_{z}\right)^{T}=\left(\begin{array}{lll}
0, & 0, & a_{2}+a_{3}+a_{4}+a_{5}
\end{array}\right)^{T},
$$

which confirms the correctness of the basic theoretical provisions. The geometric meaning of the proof is that for the cases described, the robot is, respectively, in a horizontal or vertical position, and its projection on the $x$ or $z$ axis is equal to the total length of the links.

Fig. 4 schematically shows the results of checking the proposed equations in the environment of virtual mathematical modeling Webots, which confirmed the proof of their correctness.

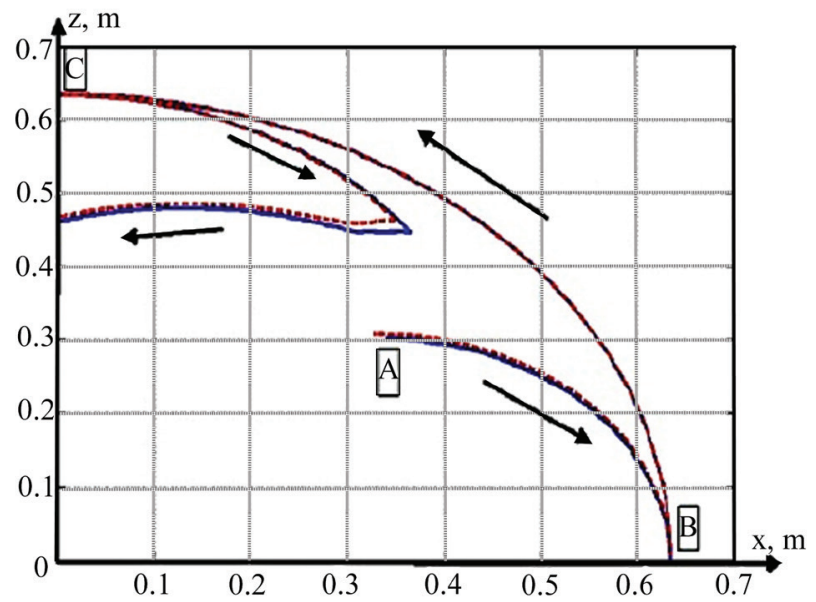

Fig. 4. The trajectory of the gripping movement from the initial position (point A) to horizontal (B) and vertical (C) with and without a gap (solid line) and without (dashed)

The proposed equations were checked in two cases: the first, when taking into account the gap, and the second, without taking into account the gap. The projections of the position vector were calculated for the initial state, after turning the fourth link to a horizontal position, as well as for the case of vertically straightened robot. It was found that the trajectory of the gripping movement from the initial position (point A) to the horizontal (point B) and vertical (point C), with and without the gap, do not coincide in two cases. The trajectory of the gripping movement from the initial position with allowance for the gap is less than without. However, when the manipulator is transferred to a vertical position, the picture is completely opposite - when the gap is taken into account, the trajectory of movement increases, a deviation from the specified theoretical trajectory of movement (without gap) is observed. Let's believe that this is due to the fact that the presence of a gap leads to loosening of the links of the system and a loss of the rigidity of their articulation, which is necessary for accurate manipulation. It has been experimentally found that the gap is $5^{\circ}(0.035) \mathrm{rad}$ in the robot joints significantly affects the movement of the gripping, negatively affecting the accuracy of its positioning.

It should be noted that this study has certain limitations, since the mathematical model was developed only for a robot that possesses five degrees of freedom and is located in a confined space, in which the influence of negative environmental factors is minimized. For optimal use of this type of robots in warehouses, it is necessary to 
pay attention to the importance of taking into account the amount of gap in the robot joints, since neglecting these indicators will lead to a decrease in robot productivity. The development of this work is the introduction of additional input values and rules to improve the control accuracy of robots with five degrees of freedom for a warehouse.

\section{Conclusions}

The study focuses on the importance of modernizing models describing the movement of a robot with five degrees of freedom for a warehouse. It is noted that one of the most problematic places is that the algorithms for controlling the robot most often contain local rules for the interaction of robots between themselves and the external environment, and emergent behavior is manifested as a result of the application of these rules, does not have a formal description. That is why an approach to creating such a model using the base coordinate system and the coordinate system of each link is presented. It is noted that for a robot with five degrees of freedom, six coordinate systems are defined, namely $\left(x_{0}, y_{0}, z_{0}\right),\left(x_{i}, y_{i}, z_{i}\right), \ldots$, $\left(x_{6}, y_{6}, z_{6}\right)$,where $\left(x_{0}, y_{0}, z_{0}\right)$ - the base «zero» coordinate system. To describe the rotational and translational connections between adjacent links, the matrix method of sequential construction of coordinate systems associated with each link of the kinematic chain was used. Each coordinate system was formed based on three rules. Let's also noted that the $i$-coordinate system is rigidly associated with the $i$-link, and the link cannot be the last one. Four geometric parameters are given, on which the rotational or translational movement of the robot depends. On the basis of theoretical ideas, an orthonormal robot coordinate system was formed, in which the coordinate systems are numbered in ascending order from the base to the robot gripping, and the values of the moments of each robot joint were obtained. Using the matrix method, the sequence of constructing coordinate systems is described and its mathematical description is given. As a result of calculations, homogeneous transformation matrices of coordinate systems of links of three robot configurations were obtained and it was indicated that the transformation matrices of coordinates from the first to fourth links ${ }^{0} A_{1}-{ }^{4} A_{4}$ are identical for all three robot configurations, and matrix ${ }^{4} A_{5}$ does not make sense for robot configuration. The definition of the homogeneous matrix ${ }^{0} T_{i}$ is carried out, with the help of which the position of the $i$-coordinate system relative to the base one is determined, and for $i=5$, the matrix $T={ }^{0} A_{5}$ is obtained, which is called the «robot matrix». Taking into account the boundaries for the robot in relative coordinates for each joint, the final equations are obtained, which make it possible to determine the final positions of gripping on the basis of the coordinates of individual joints of the robot $\theta_{i}$. It is proposed to take into account the presence of a gap at the exit of the joints, as the sum of $\delta \theta_{i}\left(M_{i}\right)$ of the function of the attached angle deviation, which describes the gap in the $i$-joint and the $\delta \theta_{i}\left(M_{i}\right)$ angles before the gap. An assessment of the model's behavior with the initial gap $\delta=0$ was carried out, based on the projections of the gripping position vector, which confirmed the correctness of the main theoretical provisions. The proposed equations were checked in two cases: the first - when taking into account the gap and the second - without taking into account the gap. A feature of the results obtained is that the trajectory of the gripping movement from the initial position to the horizontal and vertical, with and without the gap, do not coincide in two cases. This is with the trajectory of the gripping movement from the initial position and when the manipulator is transferred to the vertical position. It has been experimentally found that the gap is $5^{\circ}(0.035) \mathrm{rad}$ in the joints, significantly affects the movement of the grip, negatively affecting the accuracy of its positioning. The sphere of practical application of the proposed mathematical model is the construction of robot control algorithms with automatic selection of the gap, as well as robot calibration, since the choice of the optimal gap leads to an increase in the positioning accuracy of robot with five degrees of freedom. This, in turn, will lead to an increase in robot productivity by $10 \%$, which is a significant value on an industrial scale using robots in warehouses.

\section{References}

1. Hulianytskyi, L. F. (2015). Dynamichna zadacha poshuku naikorotshoho shliakhu dlia zadachi pobudovy marshrutu. Matematychne modeliuvannia v ekonomitsi, 2, 39-50.

2. Kheilo, S. V. (2014). Razrabotka nauchnykh osnov sozdaniia manipuliatsionnykh mekhanizmov parallelnoi struktury dia robototekhnicheskikh sistem predpriiatii tekstilnoi i legkoi promyshlennosti. Moscow, 292.

3. Eraki, M. T. Kh. (2019). Avtomatizirovannaia sistema upravleniia tekhnologicheskim manipuliatorom dlia rozliva i markirovki pischevykh produktov. Moscow, 120.

4. Melnyk, A. A. (2018). Kinematychna model robota z shistma stupeniamy svobody i mozhlyvistiu obliku zazoru v suhlobakh. Naukovi pratsi DonNTU, 10 (180), 112-120.

5. Galemov, R. T., Sochnev, A. N. (2015). Modernizatsiia sistemy upravleniia promyshlennogo robota «TUR-10K». Prospekt Svobodnii-2015. Krasnoiarsk, 8-11.

6. Zaritskyib, O. V. (2015). Klasyfikatsiia suchasnykh informatsiinykh system modeliuvannia. Visnyk Chernihivskoho Derzhavnoho Tekhnolohichnoho unstytutu, 1 (77), 98-107.

7. Syriamkin, V. I. (Ed.) (2018). Kollektivy intellektualnykh robotov. Sfery primeneniia. Tomsk: STT, 140.

8. Siciliano, B., Khatib, O. (2008). Handbook of robotics. Berlin Heidelberg: Springer-Verlag, 1611. doi: http://doi.org/10.3390/ app11073105

9. Pivniak, H. H., Protsenko, S. M., Stadnik, M. I., Tkachov, V. V. (2007). Detsentralizovane keruvannia. Donetsk: Natsionalnyi hirnychyi universytet, 107.

10. Hunchenko, Yu. O., Muliar, I. V. (2015). Metod pobudovy intelektualnykh system planuvannia peremishchennia mobilnoho robota v nevidomomu seredovyshchi. Zbirnyk naukovykh prats Viiskovoho instytutu KNU im. T. Shevchenka, 50, 23-28.

11. Angelo, J. A. (2007). Robotics: A Reference Guide to the Ner Technology. Westport: Greenwood Press, 417.

$\triangle$ Volodymyr Shvets, Postgraduate Student, Department of Cyberphysical and Information-Measuring Systems, National Technical University «Dnipro Polytechnic», Dnipro, Ukraine, ORCID: https:// orcid.org/0000-0002-7552-3215, e-mail: shvets.vo.s@nmu.one

Viktor Tkachov, Doctor of Technical Sciences, Professor, Head of Department of Cyberphysical and Information-Measuring Systems, National Technical University «Dnipro Polytechnic», Dnipro, Ukraine, ORCID: https://orcid.org/0000-0002-2079-4923

$\triangle$ Corresponding author 